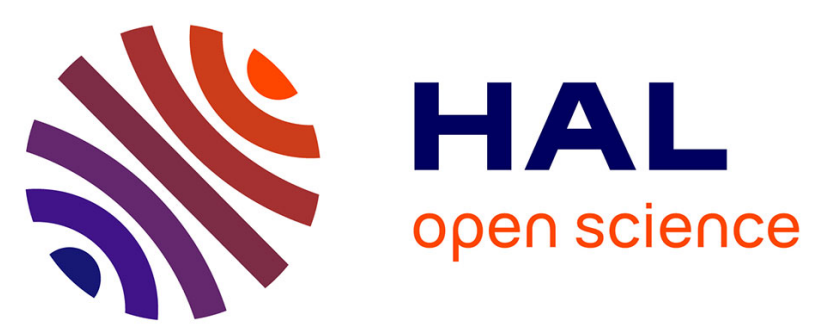

\title{
Application of photothermal mathods to the measurements of glass transition and viscoelasticity of polymers
}

\author{
A. Cournoyer, D. Lévesque, L. Piché, L. Bertrand
}

\section{To cite this version:}

A. Cournoyer, D. Lévesque, L. Piché, L. Bertrand. Application of photothermal mathods to the measurements of glass transition and viscoelasticity of polymers. Journal de Physique IV Proceedings, 1994, 04 (C7), pp.C7-241-C7-244. 10.1051/jp4:1994757 • jpa-00253286

\section{HAL Id: jpa-00253286 https://hal.science/jpa-00253286}

Submitted on 1 Jan 1994

HAL is a multi-disciplinary open access archive for the deposit and dissemination of scientific research documents, whether they are published or not. The documents may come from teaching and research institutions in France or abroad, or from public or private research centers.
L'archive ouverte pluridisciplinaire HAL, est destinée au dépôt et à la diffusion de documents scientifiques de niveau recherche, publiés ou non, émanant des établissements d'enseignement et de recherche français ou étrangers, des laboratoires publics ou privés. 


\title{
Application of photothermal methods to the measurements of glass transition and viscoelasticity of polymers
}

\author{
A. Cournoyer, D. Lévesque*, L. Piché* and L. Bertrand \\ Department of Engineering Physics, Ecole Polytechnique de Montréal, C.P. 6079, Succ. Centre-Ville, \\ Montréal, Québec, Canada, H3C $3 A 7$ \\ * Industrial Materials Institute, 75 boulevard de Mortagne Boucherville, Québec, Canada, J4B 6Y4
}

\begin{abstract}
The glass transition temperature $T_{g}$ can be identified with a sharp increase of the thermal expansion coefficient $\chi$. We present photoacoustic and constrained photodeformation measurements of the glass transition in polystyrene in conditions of weak optical absorption. Since the thermoelastic contribution to the signal prevails in those conditions, we show both theoretically and experimentally that the signal amplitudes exhibit a sharp increase near $T_{g}$, allowing its clear identification and the observation of a viscoelastic behavior.
\end{abstract}

\section{INTRODUCTION}

Numerous theories exist for the glass transition, but none of them explains that phenomenon completely. Moreover, a glass transition seems to be a kinetic process rather than a pure phase transition. This is supported by theoretical works [1] on nonlinear volume and temperature relaxation in the vicinity of the glass transition temperature $T_{g}$ in polymers. A method of measurement allowing a better understanding of that physical phenomenon would be important for theoretical advances as well as for technical applications of polymers. On the other hand, from a thermodynamic point of view, the thermal expansion coefficient $\chi$ is an important material property to measure since, according to Sharma [2], various parameters describing the thermoacoustic and anharmonic properties can be calculated employing only $\chi$ near $T_{g}$ (viz. Sharma and Gruneisen parameters). Thus, there exists an interest in a nondestructive measurement of $\chi$.

Photothermal methods allow the measurement of thermal properties such as the heat capacity $c_{p}$ and the thermal conductivity $k$. For this reason, interesting works have been published on phase transitions using those techniques after the pioneering work of Florian et al. [3]. To our knowledge, the first and main work on glass transition in polymers using photoacoustics is due to Korpiun et al. [4]. Their measurement was made in conditions of strong optical absorption and relatively large cell gas volume. The amplitude of the acoustic signal, measured as a function of temperature, showed a variation essentially due to the increase of $c_{p}$ in the vicinity of $T_{g}$.

In recent work Lévesque et al. [5] theoretically showed, solving the coupled thermoviscoelastic equations using the finite element method, that both the glass transition and the viscoelastic relaxation in polystyrene could be clearly observed. The glass transition is associated with a sharp increase of the signal amplitude at $T_{g}$, resulting from a sharp increase of $\chi$ at that temperature. The viscoelastic behavior 
is associated with a characteristic decrease of the signal amplitude, which is a function of frequency, for $\mathrm{T}>\mathrm{T}_{\mathrm{g}}$. Their theoretical results showed the importance of the thermoelastic contribution to the photoacoustic signal for the measurement of phase transitions, as previously stressed by Junge et al. [6].

\section{NUMERICAL SIMULATIONS OF PA AND CPD SIGNALS}

The details concerning the numerical solution of the coupled thermoviscoelastic equations are given elsewhere [5,7]. Those equations, in the Laplace transform domain, are

$$
\begin{gathered}
\mathbf{k} \nabla^{2} \theta^{*}-\rho \mathrm{sc}_{\mathbf{v}}{ }^{*} \theta^{*}=\mathrm{K}^{*} \chi \mathrm{T}_{0} \mathrm{~s} \nabla \cdot \mathbf{u}^{*}-\mathrm{Q}^{*}, \\
\mu^{*} \nabla^{2} \mathbf{u}^{*}+\left(\lambda^{*}+\mu^{*}\right) \nabla\left(\nabla^{*} \mathbf{u}^{*}\right)-\rho \mathrm{s}^{2} \mathbf{u}^{*}=\mathrm{K}^{*} \chi \nabla \theta^{*}-\rho \mathbf{g}^{*}
\end{gathered}
$$

where the temperature deviation from $T_{0}, \theta^{*}$, and the displacement vector, $u^{*}$, are the variables; $k$ is the thermal conductivity; $\rho$, the mass density; $\chi$, the thermal expansion coefficient; $\mathbf{c}_{\mathrm{v}}{ }_{\mathrm{v}}^{*}$, the complex specific heat at constant volume; $\lambda^{*}$ and $\mu^{*}$, the complex Lamé coefficients; $K=\lambda^{*}+2 \mu^{*} / 3$, the complex bulk modulus; $\mathrm{g}^{*}$, the body forces and $\mathrm{s}$, the Laplace parameter. $\mathrm{Q}^{*}$ is the internal heat source, due to the optical absorption of a sinusoidally modulated gaussian laser beam (diameter of $2 \mathrm{~mm}$ approximately).

For the case of the photoacoustic (PA) method, equations (1) and (2) are solved for both sample (polystyrene) and gas (air) and the signal is given by the amplitude of the modulated pressure $\mathrm{p}^{*}=\mathrm{K}^{*}\left(\chi \theta^{*}+\nabla \cdot \mathbf{u}^{*}\right)[5]$. Figure 1 shows the signal amplitude for an atactic polystyrene sample (diameter $10 \mathrm{~mm}$, length $27 \mathrm{~mm}$ ), a gas length of $0.5 \mathrm{~mm}$ and a modulation frequency of $10 \mathrm{~Hz}$. Following previous work [5], we assumed typical temperature dependance for the material parameters. For the needs of the numerical simulation, the sharp increase of $\chi$ near $T_{g}$ is set at $373 \mathrm{~K}$.

The normalized signal amplitude shown in figure 1 is the ratio of the signals at a given temperature and at $T_{g}=373 \mathrm{~K}$. PA response was calculated for various optical absorption coefficients $\beta$. The numerical simulation clearly shows that the increase in the signal amplitude near $\mathrm{T}_{\mathrm{g}}$ is proportionnally much more important for low optical absorption. A drop in the signal occurs for $\mathrm{T}>\mathrm{T}_{8}$ a conjugated effect of the increase of $c_{p}$ and the rapid change of the mechanical properties of polystyrene near $\mathrm{T}_{\mathrm{g}}$. However, this effect is much more obvious for low optical absorption. This last result enables the observation of the thermoelastic contribution to the signal (in opposition to the thermoacoustic contribution mainly observed in [4]); therefore, we chose to make our measurements at low optical absorption.

We also conducted simulations for constrained photodeformation (CPD). In this experimental scheme (presented for the first time to our knowledge), a membrane is used to constrain the surface of the sample in photothermal deformation. There are three main reasons for that. The first is experimental: near $\mathrm{T}_{g}$ the position of the surface of the heated sample highly fluctuates; the membrane thus stabilizes the surface. Secondly, thermoelastic effects do not compete with thermoacoustic ones (heat diffusion in the coupling gas in PA) in photodeformation experiments. Finally, a mechanical work is executed by the sample in periodic thermal expansion against the constraining membrane in $\mathrm{CPD}$, allowing the observation of the collapse of the mechanical properties near $T_{\mathrm{g}}$. This is similar to the work done by the sample against the closed gas volume in a PA cell.

Figure 2 shows results for a simulated CPD experiment. The conditions are similar to the case of PA, except that equations (1) and (2) are solved for the same polystyrene sample and a $12 \mu \mathrm{m}$ thick $\mathrm{Kapton}^{\mathbb{8}}$ membrane (exhibiting very stable mechanical and thermal properties in the range of temperature of interest [8]). In particular, thermal expansion is negligeable in comparison to polystyrene. The circular membrane is clamped and continuity of normal displacement and stress is assumed at the 
sample-membrane boundary. The general behavior of CPD signal amplitude (taken as the normal displacement $u_{z}$ at the center of the constraining membrane) is clearly similar to PA signal (compare figures 1 and 2 for an optical absorption $\beta=0.5 \mathrm{~cm}^{-1}$ and a modulation frequency of $10 \mathrm{~Hz}$ ). That figure also shows, based on the Vogel-Tammann-Fulcher relaxation law [5], that the drop in the signal for $T>T_{g}$ occurs at a higher temperature for an increasing modulation frequency, which is typical of a viscoelastic behavior. The same behavior was observed for PA simulations at low optical absorption. For high values of $\beta$, we observed that the important drop in the signal amplitude is much less striking, and is due to the increase of $c_{p}$ near $T_{g}$.

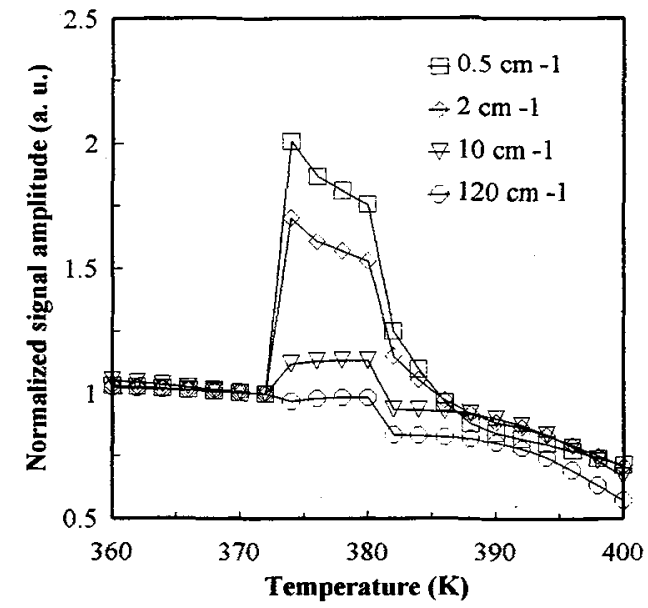

Figure 1 Simulated PA signal as a function of temperature for different values of $\beta$

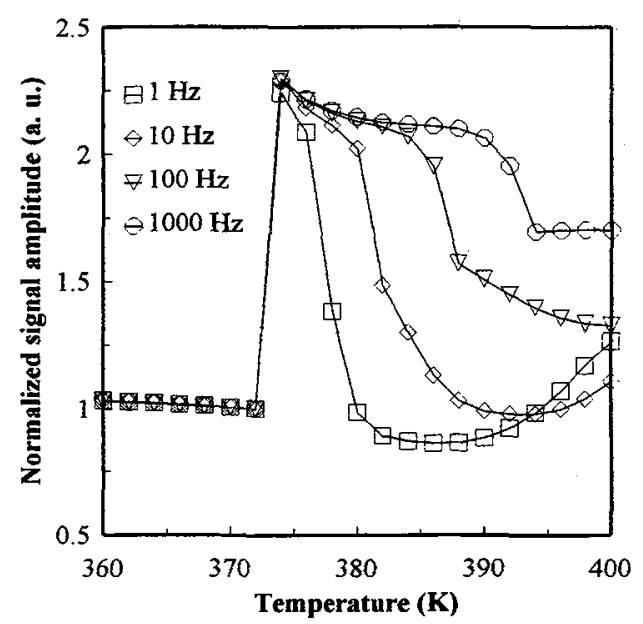

Figure 2 Simulated CPD signal for $\beta=0.5 \mathrm{~cm}^{-1}$ and for different modulation frequencies

\section{EXPERIMENT}

PA and CPD experimental measurements have been carried out in conditions of low optical absorption $\left(\beta \approx 0.5 \mathrm{~cm}^{-1}\right.$ for $\lambda=0.6328 \mu \mathrm{m}$ (HeNe laser) and $\lambda=1.064 \mu \mathrm{m}\left(\mathrm{Nd}^{3+}\right.$-YAG laser) ). The PA cell has been designed to reduce the residual volume (the microphone is attached to the $\mathrm{CaF}_{2}$ window), to enable the expansion of the gradually heated sample (air gas length: $3 \mathrm{~mm}$ ) and to keep the ambiant pressure at the atmosphere. Details of that special PA cell will be given elsewhere. The experimental setup for CPD measurements is illustrated in figure 3. The schlieren detection method we used to measure the periodic displacement of the membrane was inspired by the laser shlieren microphone of Choi et al. [9], and first presented for photodeformation measurements by Saito et al. [10]. In that technique, the insertion of an iris in front of the detection photodiode transforms the divergence induced in the probe beam by the deformation of the constraining membrane into an intensity variation, proportional to the photodeformation.

Results are shown in figure 4. The sample was a Polysar $204^{\circledR}$ atactic polystyrene (Vicat softening point $T_{v}=107^{\circ} \mathrm{C}$ ). PA measurement was made with a $40 \mathrm{~mW} \mathrm{Nd} d^{3+}-$ YAG pump laser (beam diameter: $2 \mathrm{~mm}$ ). For CPD measurements (two sets of data in identical conditions show the reproducibility of the experiment), HeNe lasers were used for pump $(20 \mathrm{~mW}$, diameter of $100 \mu \mathrm{m})$ and probe $(4.5 \mathrm{~mW}$, diameter of $700 \mu \mathrm{m}$ ). It is clearly shown that the main features of figures 1 and 2 are experimentally observed. PA and CPD measurements are very similar, but since the PA signal was noisy, we had to average it, while the CPD signal presents a high signal-to-noise ratio. In both cases, a jump in the signal amplitude occurs at $107^{\circ} \mathrm{C}$, which is consistent with $T_{r}$. The maximum of the signal is shifted toward higher temperatures for increasing variation rate of the ambiant temperature, which is typical of glass transition. 
Finally, a decrease of the signal is observed for $T>T_{g}$, a characteristic of the viscoelastic behavior of polymers.

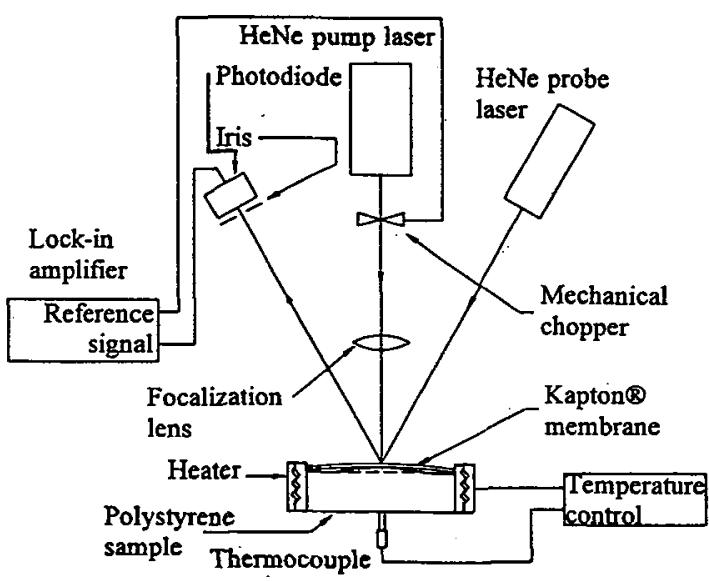

Figure 3 CPD experimental setup for the measurement of $\mathrm{T}_{\mathrm{g}}$

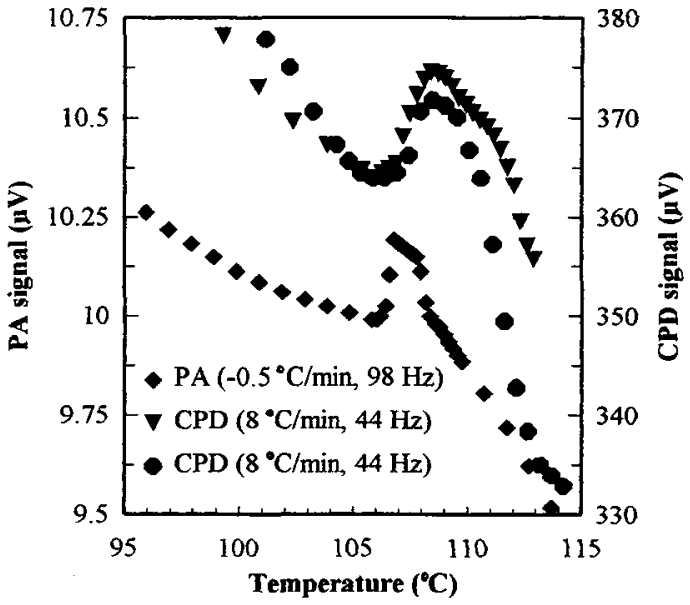

Figure $4 \mathrm{PA}$ and CPD signals for polystyrene at the vicinity of $T_{g} \approx 107^{\circ} \mathrm{C}$

\section{CONCLUSION}

PA and CPD experiments support the evidence that thermoelastic effects are dominant at low optical absorption, allowing the identification of $T_{\mathrm{g}}$. A quantitative measurement of $\chi$ and viscoelastic properties of polymers should be possible after calibration of the optical probe and comparison with absolute values for the membrane deformation from the numerical simulations (not shown here). The simple CPD technique is also demonstrated to be a more efficient method than PA. Work is in progress to study the influence of modulation frequency on the measurement of the glass transition.

\section{ACKNOWLEDGEMENTS}

This research was supported by the Natural Sciences and Engineering Research Council of Canada (strategic grant STR 45620). Special thanks go to Olivier Amaud for data acquisition.

\section{REFERENCES}

[1] Baur H., Rheol. Acta 28 (1989) 333-349.

[2] Sharma B.K., phys. stat. sol. (a) 130 (1992) 335-342.

[3] Florian R., Pelzl J., Rosenberg M., Vargas H., Wernhardt R., phys. stat. sol. (a) 48 (1978) K35-K38.

[4] Korpiun P., Tilgner R., Schmidt D., J. Phys. France 44 Colloq. C6 (1983) C6-43 - C6-53.

[5] Lévesque D., Bertrand L., Piché L., Springer Series in Optical Sciences 62 (Murphy, MaclachlanSpicer, Aamodt, Royce eds.) (1990) 294-296.

[6] Junge K., Bein B., Pelzl J., J. Phys. France 44 Colloq. C6 (1983) C6-55 - C6-59.

[7] Lévesque D. and Bertrand L., Int. J. Num. Meth. Engng. 29 (1990) 953-968.

[8] Du Pont Co., Kapton technical data.

[9] Choi J.G. and Diebold G.J., Appl. Opt. 21 (1982) 4087-4091.

[10] Saito H., Irikura M., Haraguchi M., Fukui M., Appl. Opt. 31 (1992) 2047-2054. 